\title{
Coupling multiplex RT-PCR to a gene chip assay for sensitive and semiquantitative detection of severe acute respiratory syndrome-coronavirus
}

\author{
Jyh-Lyh Juang ${ }^{1}$, Tsan-Chi Chen ${ }^{1,5}$, Shih Sheng Jiang ${ }^{2}$, Chao A Hsiung ${ }^{3}$, Wei-Chen Chen ${ }^{3}$, \\ Guang-Wu Chen ${ }^{3}$, Shiang-Ming Lin ${ }^{1}$, Jih-Hui Lin ${ }^{4}$, Shu-Chun Chiu ${ }^{4}$ and Yiu-Kay Lai ${ }^{5}$ \\ ${ }^{1}$ Division of Molecular and Genomic Medicine, National Health Research Institutes, Taipei, Taiwan; \\ ${ }^{2}$ President's Laboratory, National Health Research Institutes, Taipei, Taiwan; ${ }^{3}$ Biostatistics and \\ Bioinformatics, National Health Research Institutes, Taipei, Taiwan; ${ }^{4}$ Center for Disease Control, Department \\ of Health, Taipei, Taiwan and ${ }^{5}$ Department of Life Science and Institute of Biotechnology, National Tsing Hua \\ University, Hsinchu, Taiwan
}

\begin{abstract}
An early and accurate diagnostic assay for severe acute respiratory syndrome (SARS) is crucial for infection control. However, most of the diagnostic methods available today, such as real-time reverse transcriptasepolymerase chain reaction (RT-PCR), require a second detection method for confirmation because they detect a single sequence region of the SARS-coronavirus (SARS-CoV). For sensitive and accurate early diagnosis, we report a novel assay system combining multiplex RT-PCR and a diagnostic gene chip to detect multiple virusspecific genomic sequences of SARS-CoV. With 53 clinical specimens, we successfully demonstrate that this technique offers not only a high-accuracy diagnosis for early SARS infection but also a semiquantitative assay. Laboratory Investigation (2004) 84, 1085-1091, advance online publication, 14 June 2004; doi:10.1038/labinvest.3700136
\end{abstract}

Keywords: SARS; coronavirus; gene chip; multiplex RT-PCR; semiquantitation

Severe acute respiratory syndrome (SARS) is a novel worldwide infectious disease, caused by a newly identified coronavirus, SARS-CoV. ${ }^{1-3}$ As this disease is rapidly spreading with a relatively high mortality rate (close to $10 \%$ ), and tends to spread within hospitals or communities, accurate diagnosis in the early course of illness and isolation of suspect cases for appropriate clinical care becomes the best strategy for the control of possible recurrent SARS outbreaks. ${ }^{4}$

However, the viral dynamics and pathogenesis of SARS-CoV in vivo has mostly remained unknown. It is believed that the incubation period of SARS can range from 2 to 16 days before the onset of symptoms, and the viral load during the first week of the illness is low. ${ }^{5}$ Therefore, the disease stage of

Correspondence: Dr J-L Juang, PhD, Division of Molecular and Genomic Medicine, National Health Research Institutes, 128, Yen-Chiu-Yuan Road, Sec 2, Taipei 115, Taiwan.

E-mail: juang@nhri.org.tw

Received 26 March 2004; revised and accepted 29 April 2004; published online 14 June 2004 the patient may greatly affect the diagnostic accuracy of a chosen assay. Serological testing has been shown to be very reliable for confirmation of the diagnosis of SARS-CoV. To date, there are two prevailing serological diagnostic methods, enzymelinked immunosorbent assays (ELISA) ${ }^{6,7}$ and indirect immunofluorescence assays (IFA), ${ }^{6,8}$ which are very suitable for the SARS diagnosis while the virus titer is relatively high in convalescent phase. ${ }^{3}$ For early diagnosis, which is critical for the control of disease spread, real-time reverse transcriptase-polymerase chain reaction (RT-PCR) becomes the prevailing option because of its higher sensitivity for the detection of a lower virus titer in the early infection. ${ }^{9}$ Nonetheless, this PCR-based assay only identifies one region of the SARS-CoV sequence per reaction. As suggested by the WHO (http:// www.who.int/csr/sars/diagnostictests/en/) and the Centers for Disease Control and Prevention, USA (http://www.cdc.gov/ncidod/sars/labdiagnosis.htm), the detection of more than one genome region with different primer sets (or by another diagnostic method) is required to confirm the SARS infection. To overcome this limitation, the multiplex RT-PCR 
(MRT-PCR) seems to be a good alternative because it can simultaneously detect multiple target sequence regions of a pathogen genome in one assay. For several respiratory infectious diseases, this method has been reported useful in detecting viruses,${ }^{10}$ such as influenza, ${ }^{11-13}$ parainfluenza, ${ }^{14,15}$ and respiratory syncytial viruses (RSV). ${ }^{12,15}$ However, some practical problems, including poor sensitivity and specificity, limit this method as a general diagnostic tool.

As gene chip technology requires hybridization with its sequence-specific probes to allow for specific and sensitive detection of targets, it is emerging as a powerful tool for the diagnosis of infectious pathogens. ${ }^{16}$ Gene chip protocols can also be coupled with PCR amplification technique to increase the sensitivity of diagnosis. Here, we show a complementary method, which combines the advantages of MRT-PCR and gene chip systems for the SARS early diagnosis.

\section{Materials and methods}

\section{Extraction of Viral RNA}

Viral RNA was extracted from the supernatant fraction of viral culture medium and its concentration was determined using the RealArt ${ }^{\mathrm{TM}}$ HPACoronavirus LC RT-PCR Reagents (Artus, USA) according to the manufacturer's instructions. The titer of calibrated viral RNA was adjusted to $1.0 \times 10^{6}$ copies $/ \mu$ l as RNA stock. To create a set of
RNA standards, the viral RNA stock was serially diluted in a 10-fold manner to give various concentrations ranging from $10^{6}$ to $10^{0}$ copies/ $\mu \mathrm{l}$. To isolate viral RNA from clinical specimens, throat swabs of clinical cases were collected by contracted hospitals of the Center for Disease Control, Taiwan during May 2003. Viral RNA was extracted from $200 \mu \mathrm{l}$ of viral transport medium with the QIAamp Viral RNA Mini Kit (Qiagen, USA) according to the manufacturer's instructions and eluted in $50 \mu \mathrm{l}$ of RNase-free water, and frozen at $-70^{\circ} \mathrm{C}$ until use.

\section{Gene Chip Design}

Three virus-specific probes (SCP1, SCP2, and SCP3) for SARS-CoV were designed (Table 1) by alignment of genomic sequences of several documented strains of SARS-CoV to decide on three distinct 60-nucleotide sequence regions so that each of them is conserved through SARS-CoV strains, while unique among genomic sequences of all species available in GenBank database at NCBI. In addition to the three SARS-CoV-specific probes, we also designed three control probes (RTCP, HCP, and NCP) for RT-PCR, hybridization, and negative control, respectively (Table 1). Each of the six synthetic 60-mer oligonucleotides was dissolved in spotting solution and spotted onto CMT-GAPS ${ }^{\text {TM }}$ slide (Corning, USA) in triplicate.

Table 1 Sequence-specific probes and primers used for the gene chip-based detection of SARS-CoV

\begin{tabular}{|c|c|c|c|c|}
\hline Fragment & Polarity $^{\mathrm{a}}$ & Sequence $\left(5^{\prime}-3^{\prime}\right)$ & $\begin{array}{l}\text { Length } \\
\text { (mer) }\end{array}$ & $\begin{array}{l}\text { Product } \\
\text { (bp) }\end{array}$ \\
\hline \multicolumn{5}{|l|}{ Probe $^{\mathrm{b}}$} \\
\hline SCP1 & $\mathrm{S}$ & TGGCTGTAGTTGTGACCAACTCCGCGAACCCTTGATGCAGTCTGCGGATGCATCAACGTT & 60 & \\
\hline SCP2 & $\mathrm{S}$ & ACTCTGTGCTCTACAACTCAACATTTTTTTCAACCTTTAAGTGCTATGGCGTTTCTGCCA & 60 & \\
\hline SCP3 & $\mathrm{S}$ & GGTGGTGAAACTGCCCTCGCGCTATTGCTGCTAGACAGATTGAACCAGCTTGAGAGCAAA & 60 & \\
\hline RTCP & $\mathrm{S}$ & GGTCCGAAGGTTTCACCATCACTGGCTCGCСTCTCAACGATTTCCGTAAACTTTGGCCСC & 60 & \\
\hline HCP & $\mathrm{S}$ & AGCATTCCGAGTAACTCCTCAACCTGGAGTTCCACCTGAAGAAGCAGGGGCCGCGGTAGC & 60 & \\
\hline NCP & S & TGTCGTAACGGGCAACTCTGCAGCGGAACCGACTACTTTGGGTGTCCGTGTTTCCTTTTA & 60 & \\
\hline \multicolumn{5}{|l|}{ Primer $^{\mathrm{c}}$} \\
\hline \multirow[t]{2}{*}{ SC1 } & $\mathrm{S}$ & AGAAACACAGTCTGTACCGT & 20 & 183 \\
\hline & A & AAGCCCTGTAGACGACATCA & 20 & \\
\hline \multirow[t]{2}{*}{ SC2 } & $\mathrm{S}$ & AAATTCCСTTCTGTCTATGC & 20 & 478 \\
\hline & A & GGTAGCCAATGCCAGTAGTG & 20 & \\
\hline \multirow[t]{2}{*}{ SC3 } & $\mathrm{S}$ & GCAGTCAAGCCTCTTCTCGC & 20 & 228 \\
\hline & A & ATGCCTCAGCAGCAGATTTC & 20 & \\
\hline \multirow[t]{2}{*}{ RTC } & $\mathrm{S}$ & TGAAAACATCCCTCTCATCG & 20 & 616 \\
\hline & A & GACCCAACCAAGATCATCGC & 20 & \\
\hline \multirow[t]{2}{*}{ HC } & $\mathrm{S}$ & GTAAGTCCATCGGTCCATAC & 20 & 141 \\
\hline & A & GAGTACCAAACCAAGGATAC & 20 & \\
\hline \multirow[t]{2}{*}{ NC } & $\mathrm{S}$ & CCTCCGGCCCCTGAATGCGG & 20 & 154 \\
\hline & A & ATTGTCACCATAAGCAGCCA & 20 & \\
\hline
\end{tabular}

${ }^{\mathrm{a}} \mathrm{S}$, sense strand; A, antisense strand.

${ }^{\mathrm{b}}$ SCP, SARS-CoV probe; RTCP, RT-PCR control probe of the Arabidopsis GA4 gene; HCP, hybridization control probe of the plant chloroplast $r b c L$ gene; NCP, negative control probe of the Picornavirus $5^{\prime}$-UTR region.

${ }^{\mathrm{C}}$ SC, SARS-CoV; RTC, RT-PCR control; HC, hybridization control; NC, negative control. 
Multiplex Reverse Transcriptase-Polymerase Chain Reaction (MRT-PCR)

To produce cDNA from viral RNA, a mixture of $1 \mu \mathrm{l}$ extracted viral RNA and $10 \mathrm{pmol}$ of each primer (Table 1) in final $10 \mu \mathrm{l}$ of solution was heated to $70^{\circ} \mathrm{C}$ for $5 \mathrm{~min}$ and then cooled down on ice for $3 \mathrm{~min}$ and then added with $10 \mu \mathrm{l}$ of reaction mixture $(4 \mu \mathrm{l}$ M-MLV reverse transcriptase reaction buffer ( $5 \times$; Promega Inc., USA), $1 \mu \mathrm{l}$ dNTP mix $(10 \mathrm{mM}$ each), $0.5 \mu \mathrm{l}$ M-MLV reverse transcriptase (100 U; Promega Inc., USA), $0.5 \mu \mathrm{l}$ RNasin ribonuclease inhibitor (20 U; Promega Inc., USA), and $4 \mu \mathrm{l}$ RNase-free water) for reverse transcription at $42^{\circ} \mathrm{C}$ for $30 \mathrm{~min}$.

The PCR reactions were performed by mixing $20 \mu \mathrm{l}$ of cDNA from previous reverse transcription with $80 \mu \mathrm{l}$ of reaction mixture $(10 \mu \mathrm{l} 10 \times$ PCR reaction buffer, $1 \mu \mathrm{l}$ Taq DNA polymerase, $1 \mu \mathrm{l}$ dNTP $\operatorname{mix}(10 \mathrm{mM})$, and $68 \mu \mathrm{l}$ distilled water) and amplified under the following conditions: an initial denaturation at $95^{\circ} \mathrm{C}$ for $2 \mathrm{~min}$, followed by 40 cycles of $95^{\circ} \mathrm{C}$ for $15 \mathrm{~s}, 55^{\circ} \mathrm{C}$ for $15 \mathrm{~s}$, and $72^{\circ} \mathrm{C}$ for $30 \mathrm{~s}$, and final extension of $72^{\circ} \mathrm{C}$ for $10 \mathrm{~min}$. The PCR products were purified using the QIAquick PCR Purification Kit (Qiagen Inc., USA) and eluted with $50 \mu$ l of distilled water.

\section{Fluorescent Dye Labeling of RT-PCR Products}

The eluted cDNAs yield from RT-PCR were added to $10 \mu \mathrm{l}$ of the reverse primer mixture $(10 \mathrm{pmol})$ (Table 1), and denatured at $95^{\circ} \mathrm{C}$ for $3 \mathrm{~min}$. After cooling down on ice for $3 \mathrm{~min}$, a $40 \mu \mathrm{l}$ of labeling reaction mixture $(10 \mu \mathrm{l}$ Klenow fragment buffer $(10 \times$; Takara Bio Inc., Japan), $0.5 \mu$ l Klenow fragment (2 U; Takara Bio Inc., Japan), $1 \mu \mathrm{l}$ dUTP mix ( $1 \mathrm{mM}$ dATP, $1 \mathrm{mM}$ dCTP, $1 \mathrm{mM}$ dGTP, and 0.5 mM dTTP), $0.5 \mu \mathrm{l} \mathrm{Cy5-}$ dUTP (1 mM; Amersham Biosciences Inc., USA), and $28 \mu \mathrm{l}$ distilled water) was added to the denatured cDNAs and incubated at $37^{\circ} \mathrm{C}$ for $30 \mathrm{~min}$ for the Cy5 labeling. The labeled probes were purified using the QIAquick PCR Purification Kit (Qiagen Inc., USA), eluted with $40 \mu \mathrm{l}$ of distilled water, and then dried by Eppendorf ${ }^{\circledR}$ Vacufuge $^{\mathrm{TM}}$ Concentrator.

\section{Gene Chip Hybridization and Image Acquisition}

The gene chip was first blocked with prehybridization solution (25\% formamide, $5 \times$ SSC, $0.1 \%$ SDS, and $1 \% \mathrm{BSA}$ ) at $42^{\circ} \mathrm{C}$ for $45 \mathrm{~min}$. The Cy5-labeled cDNA was resuspended in $6 \mu \mathrm{l}$ of hybridization solution $(25 \%$ formamide, $5 \times$ SSC, $0.1 \%$ SDS, $0.5 \mathrm{mg} / \mathrm{ml}$ of oligonucleotide, $0.5 \mathrm{mg} / \mathrm{ml}$ of yeast tRNA, and $0.5 \mathrm{mg} / \mathrm{ml}$ of salmon sperm DNA) and denatured in boiling water for $3 \mathrm{~min}$. After cooling down to room temperature, labeled cDNA was hybridized to a gene chip. The gene chip was hybridized at $42^{\circ} \mathrm{C}$ for $1 \mathrm{~h}$, and then washed sequentially with a primary solution $(2 \times$ SSC and $0.1 \%$ SDS) at $42{ }^{\circ} \mathrm{C}$ for $10 \mathrm{~min}$, a second solution $(0.1 \times$ SSC and $0.1 \%$ SDS $)$ at room temperature for $10 \mathrm{~min}$, and a final solution $(0.1 \times \mathrm{SSC})$ at room temperature for $10 \mathrm{~s}$. After a $100 \%$ ethanol alcohol rinse, the gene chip was dried with compressed air. An image of the gene chip was obtained by using a laser confocal slide scanner (GenePix ${ }^{\circledR} 4000 B$ ) and was analyzed by using GenePix ${ }^{\circledR}$ Pro software (Axon Instruments Inc., USA).

\section{Results}

\section{Designs of Primers and Probes}

To optimize the diagnostic sensitivity of early infection while the viral load in clinical specimens is still low, we amplified the copy number of virusspecific sequences by RT-PCR with specific primer pairs before hybridization detection by gene chip analysis. By careful selection of primer pairs corresponding to different regions of the viral genome (as listed in Table 1), specific and efficient amplicons with expected sizes were detected while no nonspecific band was found by gel electrophoresis (data not shown). The RT-PCR products were labeled by fluorescent dye as described in 'Materials and methods' and hybridized to the SARS-CoV gene chip. After hybridization, the fluorescent intensities of probes were determined using a laser confocal scanner. The amplified cDNA targets, including SARS-CoV and control sequences, were specifically hybridized to their corresponding probes without noticeable cross-hybridization background (Figure 1a).

To further evaluate the dynamic range of detection by the gene chip assay, serial 10-fold dilutions of calibrated SARS-CoV RNA $\left(10^{6}\right.$ copies/ $\left.\mu \mathrm{l}\right)$ were used as templates for RT-PCR amplification. The signal intensity of each probe was extracted from the gene chip for analysis. Figure $1 \mathrm{~b}$ shows the signal intensity of individual probe plotted against viral RNA input. Notably, the SCP1 and SCP3 probes are capable of detecting the PCR products with as few as a theoretically single copy of starting SARS-CoV RNA. In contrast, the SCP2 appears to be less efficient in detecting low titer virus $\left(<10^{2}\right.$ copies), suggesting that the design of the SC2 primer pair for RT-PCR amplification and/or the SCP2 probe for hybridization was not optimized for detection of trace virus. On the other hand, we also noted that the fluorescent signals of SCP1 and SCP3 plateaued early at low virus titer, whereas that of SCP2 seems to exert a wider linear dynamic range; a result that suggests that SCP2 is valuable for quantitative assay. In the same chip, we also noted that the RTCP control probe showed invariant signal magnitude to the constant input of control target (Figure 1c), thus making it a useful normalization standard for semiquantification assay. 


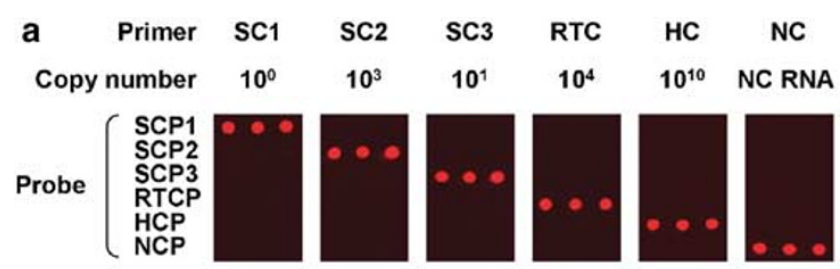

b

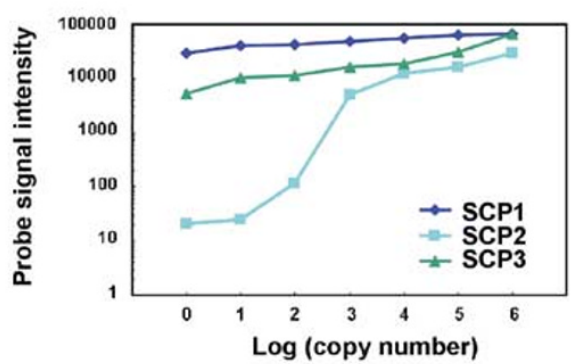

C

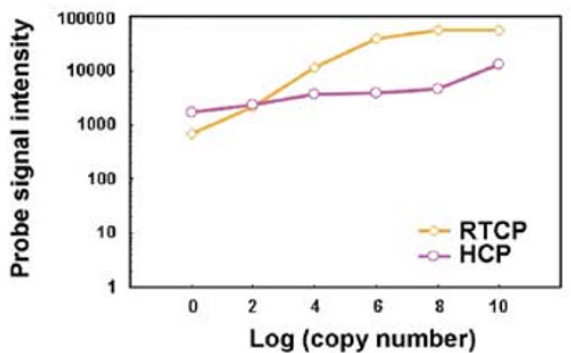

Figure 1 (a) Specific RT-PCR products were labeled with Cy5 and hybridized to the probes on the SARS-CoV gene chip. No background cross-hybridization was detected. SCP, SARS-CoV probe; RTCP, RT-PCR control probe of the Arabidopsis GA4 gene; HCP, hybridization control probe of the plant chloroplast $r b c L$ gene; NCP, negative control probe of the Picornavirus $5^{\prime}$-UTR region; SC, SARS-CoV primers; RTC, RT-PCR control primer; HC, hybridization control primer; NC, negative control primer. The dynamic range of sensitivities in detecting specific RT-PCR products by three SARS-CoV-specific probes (b) and two control probes (c).

\section{Optimization of MRT-PCR for Gene Chip Assay}

Given the fact that the specific RT-PCR amplification is compatible with the gene chip detection of SARS$\mathrm{CoV}$, we tested the feasibility of coupling MRT-PCR to the same gene chip assay. We first optimized the concentration of each primer set and RT-PCR conditions to provide highly efficient RT-PCR amplification in multiplex reactions with four primer sets. Consistent with the single RT-PCR result, the agarose gel electrophoresis analysis revealed that all but SC2 were markedly amplified (Figure 2a). The products of MRT-PCR were then labeled with fluorescent dye for the chip-based detection. The result showed that both viral and control probes were specifically hybridized to their corresponding probes (Figure $2 \mathrm{~b}$ ). In particular, the SC2 PCR amplicon, which was undetectable by the agarose gel electrophoresis (Figure 2a), became detectable by the SCP2 probe in the gene chip (Figure 2b). Clearly, the gene chip assay is more a
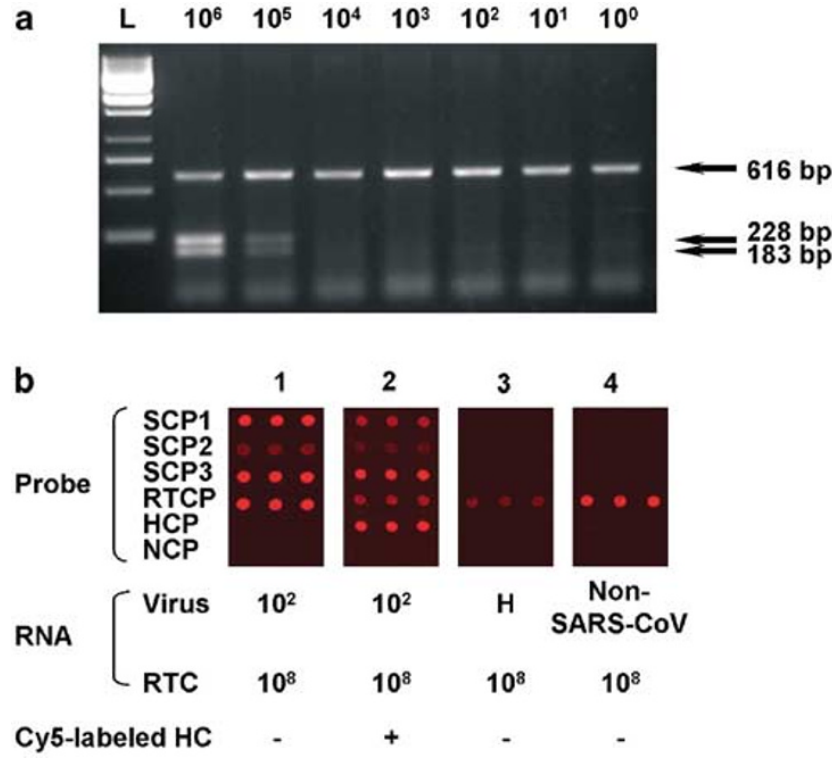

Figure 2 Coupling MRT-PCR and gene chips for detection of SARS-CoV. (a) Quadruplex RT-PCR was carried out with three virus-specific plus one RT-PCR control primer sets, serial dilutions of SARS-CoV were used as templates and amplicons were analyzed by agarose gel electrophoresis. The 616,228 , and 183 bp amplicons represent RTC, SC3, and SC1 PCR products, respectively. (b) Specific fluorescent signals on a gene chip hybridized with the Cy5-labeled MRT-PCR products; chip \#1 without hybridization control (HC); chip \#2 with HC; chip \#3 is a negative control with only human RD cell RNA (H); chip \#4 is a negative control with non-SARS-CoV RNA (non-SARS-CoV).

sensitive than conventional agarose gel electrophoresis in detecting MRT-PCR products of trace SARS-CoV.

\section{Diagnostic Accuracy of Clinical Samples}

The potential application of this chip-based assay for clinical diagnosis of SARS-CoV infection was evaluated with clinical specimens. In this study, throat swabs were randomly selected from 53 different patients who were either suspect or probable SARS cases in the Center for Disease Control, Taiwan. The definition of suspect or probable cases relies upon WHO criteria (http:// www.who.int/csr/sars/casedefinition/en/). For example, a suspect case of SARS has high fever $\left(>38^{\circ} \mathrm{C}\right.$ ), symptoms of cough or breathing difficulty, and has history of exposure or contact with person who is a suspect or probable case of SARS. In our study, the probable cases, which may represent people who had similar symptoms with those of suspect cases except the history of contact is not clear, were also included in the sampling pool. All cases were tested in single-blinded manner. In addition to chip-based assay, all specimens were analyzed in parallel by single-round RT-PCR (Artus), real-time nested PCR, ${ }^{17}$ and subsequently confirmed 
by seroconversion unless convalescent sera were not available due to the fatal cases or sera were only collected at acute phase.

Table 2 summarizes the accuracy of different diagnostic methods. Both the chip-based assay and real-time nested PCR detected 18 positive cases in 53 clinical specimens. In contrast, only 15 cases were identified as SARS-CoV-positive and three were missed by the single-round RT-PCR. Interestingly, we determined that these three missed samples contained $<10$ copies of viral genome in the test of real-time nested PCR, suggesting that the gene chip is a sensitive method to detect SARS-CoV in early infection. For those three cases missed by single-round RT-PCR (Artus) and another eight positive cases (total 11 out of 18 positive cases), infection was confirmed by seroconversion (Table 2).

\section{A Semiquantitative Method by Gene Chip}

Quantitation of viral load in clinical samples has important implications for treatment strategies. To establish a semiquantitative model for the gene chip assay of SARS-CoV, a serial 10-fold dilution of SARS-CoV RNAs was amplified by MRT-PCR and hybridized to gene chips (Figure 3a). The dynamic range of signal magnitude of each probe to different

Table 2 Comparison of 53 diagnoses of suspected or probable cases of SARS by different assays

\begin{tabular}{|c|c|c|c|c|}
\hline \multirow[t]{2}{*}{ Test } & \multicolumn{2}{|c|}{ Positive results $^{\mathrm{a}}$} & \multirow{2}{*}{$\begin{array}{l}\text { Negative } \\
\text { results }\end{array}$} & \multirow[t]{2}{*}{ Total } \\
\hline & $\begin{array}{c}>10 \text { copies } \\
\text { per test }\end{array}$ & $\begin{array}{c}<10 \text { copies } \\
\text { per test }\end{array}$ & & \\
\hline \multicolumn{5}{|c|}{ SARS-CoV gene chip } \\
\hline No. of results & 9 & 9 & 35 & 53 \\
\hline Seroconversion $^{\mathrm{b}}$ & 6 & 5 & 0 & 11 \\
\hline \multicolumn{5}{|c|}{ Real-time nested $P C R^{\mathrm{c}}$} \\
\hline No. of results & 10 & 8 & 35 & 53 \\
\hline Seroconversion ${ }^{\mathrm{b}}$ & 7 & 4 & 0 & 11 \\
\hline \multicolumn{5}{|c|}{ Single-round RT-PCR ${ }^{\mathrm{d}}$} \\
\hline No. of results & 10 & 5 & 38 & 53 \\
\hline Seroconversion $^{\mathrm{b}}$ & 7 & 1 & 3 & 11 \\
\hline \multicolumn{5}{|l|}{ Shared results } \\
\hline No. of results & $9^{\mathrm{e}}$ & 5 & 35 & 49 \\
\hline Seroconversion ${ }^{\mathrm{b}}$ & 6 & 1 & 0 & 7 \\
\hline
\end{tabular}

${ }^{\mathrm{a}}$ Results of four independent tests.

${ }^{b}$ Data are number of samples obtained from patients for whom seroconversion was also noted, by ELISA and neutralizing antibody responses for available serum samples obtained during the convalescent phase of illness (ie, $>28$ days after onset of illness).

${ }^{\mathrm{C}}$ Results obtained by real-time nested PCR. ${ }^{17}$

${ }^{\mathrm{d}}$ Results obtained by hybridization probe-based detection using the RealArt HPA-coronavirus RT-PCR kit (Artus).

${ }^{\mathrm{e}} \mathrm{A}$ total of nine samples were detected in the ' $>10$ copies per test' with the gene chip method, and 10 samples with both nested and single-round PCR methods, because the virus copy number in case 18 was underestimated (see Table 3). viral RNA input was shown by plotting the signal intensity extracted from each probe on the gene chip against the copy number of viral RNA (Figure 3b). The results reveal that three viral probes exhibited distinct linear ranges of sensitivity for detection of viral RNA concentration.

Based on the observed signals of those viral and control probes, statistical analysis was undertaken to establish a quantitative model. The average signal intensity of RTCP control in each gene chip was first adjusted with respect to the average of the RTCP controls of all gene chips, and the average intensities of SCP $i(i=1,2,3)$ on each gene chip were then normalized according to the adjusted average intensity of RTCP control. Using the logarithm of base 10 , we denote the copy number of virus as $V$, and the normalized average intensity of SCP $i$ as $F_{\mathrm{SCP} i}$ $(i=1,2,3)$. We proposed the following quantitative model for evaluation of viral load:

$$
V=a_{0}+a_{1} \times F_{\mathrm{SCP} 1}+a_{2} \times F_{\mathrm{SCP} 2}+a_{3} \times F_{\mathrm{SCP} 3}
$$

which transforms the normalized average signal intensities of SCP $i(i=1,2,3)$ into copy number of virus. Using least-squares method, the coefficients of $a_{0}, a_{1}, a_{2}$ and $a_{3}$ were estimated based on the data generated from the controlled hybridization results of titration SARS-CoV. The quantitative model can be represented as the following equation:

$$
V=-4.14+0.69 F_{\mathrm{SCP} 1}-0.05 F_{\mathrm{SCP} 2}+1.03 F_{\mathrm{SCP} 3}
$$

The value of $R^{2}$ is 0.91 , which indicates that the normalized average intensities of $\operatorname{SCP} i(i=1,2,3)$, could explain, for the most part, the variation of

a

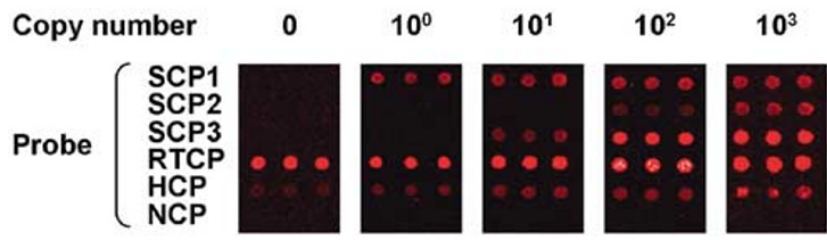

b

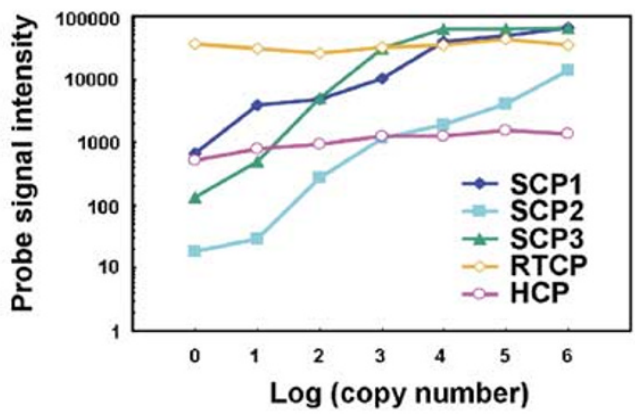

Figure 3 Range of detection sensitivities of three virus-specific probes on the gene chip. (a) Differential hybridization signal intensities of three independent SARS-CoV probes were detected using a serial dilution of viral RNA input. (b) Hybridization signal of each individual probe was plotted against the log concentration of viral RNA; order of detection sensitivity: SCP1 > SCP3 > SCP2. 
viral titers. In practice, we can predict the copy number of SARS-CoV in clinical samples by this model.

Accordingly, we tested the model with gene chips hybridized with 18 SARS-CoV-positive clinical samples. Table 3 shows that the gene chip estimates of viral RNA concentration correlates highly with the result determined by real-time nested PCR. Plots of chip-based semiquantitation and real-time nested PCR quantitation also showed good correlation (Figure 4 , correlation coefficient $=0.92$ ). Thus, the

Table 3 Quantitative analysis of viral copy number in clinical specimens by gene chip and real-time nested PCR

\begin{tabular}{|c|c|c|c|}
\hline \multirow[t]{2}{*}{ Case no. } & \multirow[t]{2}{*}{ Chip image } & \multicolumn{2}{|c|}{ Estimation of viral copy number } \\
\hline & & By gene chip ${ }^{\mathrm{a}}$ & By real-time nested $P C R^{\mathrm{b}}$ \\
\hline 1 & 0000 & 1241 & 609 \\
\hline 2 & 0.0 & 273 & 750 \\
\hline 3 & $0 \quad 0$ & 2 & 1 \\
\hline 4 & 0.0 & 32 & 18 \\
\hline 5 & 0.0 & 42 & 52 \\
\hline 6 & 000 & 123 & 869 \\
\hline 7 & 000 & 981 & 1360 \\
\hline 8 & 0.0 & 2 & 3 \\
\hline 9 & 0000 & 5653 & 2889 \\
\hline 10 & $0 \quad 0$ & 1 & 7 \\
\hline 11 & $0 \quad 0$ & 1 & 4 \\
\hline 12 & $0 \quad 0$ & 6 & 1 \\
\hline 13 & 0.9 & 10 & 7 \\
\hline 14 & $0 \quad 0$ & 6 & 1 \\
\hline 15 & 0.00 & 1407 & 1268 \\
\hline 16 & $0 \quad 00$ & 50 & 41 \\
\hline 17 & 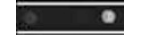 & 2 & 2 \\
\hline 18 & $0 \quad 0$ & 5 & 18 \\
\hline
\end{tabular}

${ }^{\mathrm{a}}$ The viral copy number estimated by gene chip assay equals to $10^{\mathrm{v}}$; $V=-4.14+0.69 F_{\mathrm{SCP}_{1}}-0.05 F_{\mathrm{SCP} 2}+1.03 F_{\mathrm{SCP} 3}$.

${ }^{\mathrm{b}}$ The vial quantitation was performed as described previously. ${ }^{17}$

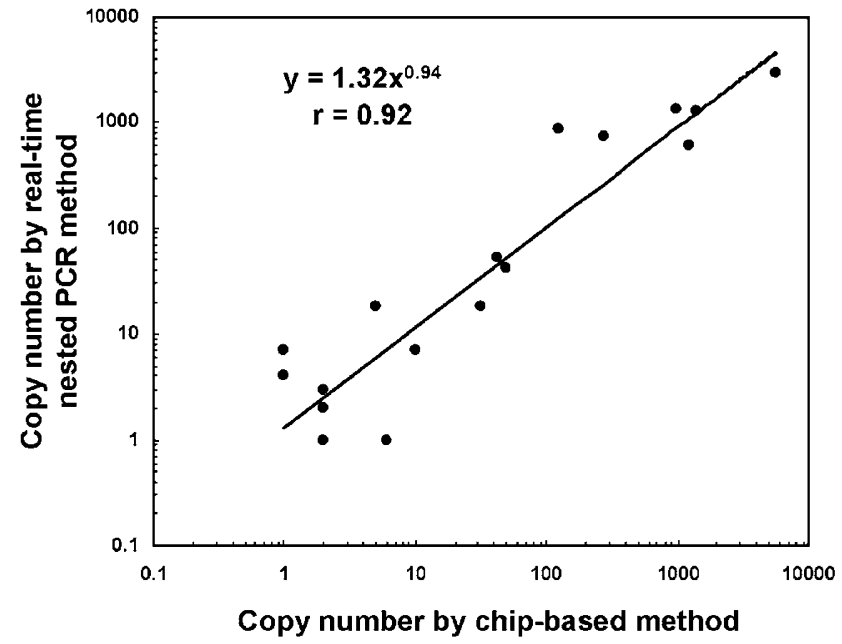

Figure 4 Correlation between virus titers determined by the chipbased assay and by a real-time nested PCR method. Viral RNA concentration was determined by gene chip and plotted against those by real-time nested PCR. The correlation coefficient $=0.92$. chip-based assay not only provides a qualitative but also a semiquantitative diagnosis of SARS-CoV in clinical specimens.

\section{Discussion}

In the present study, we report a chip-based assay for early SARS-CoV infection. We tested 53 clinical specimens and demonstrate that the gene chip can accurately detect SARS-CoV. This assay is highly specific and sensitive and is applicable to clinical samples. Our findings suggest several advantages over conventional single-round real-time RT-PCR. First, the chip-based assay is highly sensitive for detection of trace virus in early infection. We have shown that the detection sensitivity of chip-based assay ( $<10$ copies of SARS-CoV) is better than, or at least comparable to, the single-round real-time RTPCR method for diagnosis of clinical specimens. Second, the gene chip-based diagnosis is highly specific. It requires hybridization with multiple sequence-specific probes (three virus-specific and three control probes on our gene chip) to allow for specific detection of virus targets of more than one genome region. Therefore, the gene chip assay not only specifically identifies the SARS-CoV but also simultaneously confirms the diagnosis in one assay, thus reducing the false-positive and false-negative results. In contrast, conventional single-round realtime RT-PCR can only detect one virus-specific sequence per reaction without stringent hybridization with probes. Third, this assay is simple and rapid. The entire assay, including MRT-PCR and chip-based assays, can be easily completed within $6 \mathrm{~h}$, including a 3-h MRT-PCR followed by a 3-h gene chip analysis, thereby making it a clinical applicable alternative for screening of SARS-CoV in laboratories that are not equipped with a real-time PCR instrument. Although this diagnosis method requires a 3-h post-PCR process for gene chip detection, it is a more time-efficient and cost-effective assay, because this gene chip can concurrently identify the virus target and confirm the diagnosis result. Last and perhaps most importantly, one may expand the present gene chip to simultaneously detect other related coronaviruses or multiple respiratory pathogens in one assay. SARS is an acute pneumonic illness and is clinically difficult to distinguish from other types of atypical pneumonia in the absence of a clear epidemiological link to other patients with the disease. The major advantage of gene chip diagnosis is that one can add to this system a large number of alternative pathogens responsible for community-acquired pneumonia with little modification.

On the other hand, it seems clear that, if MRT-PCR primers of sufficiently broad utility cannot be designed, the extension of this technology to simultaneously detect other related pathogens will be seriously hampered because only high efficiency 
of PCR amplification can provide maximum sensitivity for detection of low titer RNA in clinical specimens. We are currently expanding the content of this gene chip to permit detection of a greater selection of viral and other pathogens.

For the semiquantitative assay by gene chip, we designed three virus-specific probes and the corresponding primer sets for a diverse range of sensitivity in detecting SARS-CoV (Figure 3). A semiquantitation model was successfully established and validated using clinical specimens to resolve the relative virus copy numbers. Taken together, our data suggest that this gene chip assay system can be ready for clinical application to detect, confirm, and semiquantify the virus in early SARS infection.

\section{References}

1 Rota PA, Oberste MS, Monroe SS, et al. Characterization of a novel coronavirus associated with severe acute respiratory syndrome. Science 2003;300: 1394-1399.

2 Marra MA, Jones SJ, Astell CR, et al. The genome sequence of the SARS-associated coronavirus. Science 2003;300:1399-1404.

3 Ksiazek TG, Erdman D, Goldsmith CS, et al. A novel coronavirus associated with severe acute respiratory syndrome. N Engl J Med 2003;348:1953-1966.

4 Chan HL, Tsui SK, Sung JJ. Coronavirus in severe acute respiratory syndrome (SARS). Trends Mol Med 2003;9: 323-325.

5 Peiris JS, Chu CM, Cheng VC, et al. Clinical progression and viral load in a community outbreak of coronavirus-associated SARS pneumonia: a prospective study. Lancet 2003;361:1767-1772.

$6 \mathrm{Wu}$ HS, Chiu SC, Tseng TC, et al. Serologic and molecular biologic methods for SARS-associated coronavirus infection, Taiwan. Emerg Infect Dis 2004;10: 304-310.
7 Che XY, Hao W, Qiu LW, et al. Antibody response of patients with severe acute respiratory syndrome (SARS) to nucleocapsid antigen of SARS-associated coronavirus. Di Yi Jun Yi Da Xue Xue Bao 2003;23: 637-639.

8 Fang LQ, Zhang PH, Yang BA, et al. The application of indirect immuno-fluorescence assay in the diagnosis of severe acute respiratory syndrome. Zhonghua Liu Xing Bing Xue Za Zhi 2003;24:484-486.

9 Drosten C, Gunther S, Preiser W, et al. Identification of a novel coronavirus in patients with severe acute respiratory syndrome. N Engl J Med 2003;348: 1967-1976.

10 Elnifro EM, Ashshi AM, Cooper RJ, et al. Multiplex PCR: optimization and application in diagnostic virology. Clin Microbiol Rev 2000;13:559-570.

11 Zou S, Stansfield C, Bridge J. Identification of new influenza $B$ virus variants by multiplex reverse transcription-PCR and the heteroduplex mobility assay. J Clin Microbiol 1998;36:1544-1548.

12 Stockton J, Ellis JS, Saville M, et al. Multiplex PCR for typing and subtyping influenza and respiratory syncytial viruses. J Clin Microbiol 1998;36:2990-2995.

$13 \mathrm{Li} \mathrm{J}$, Chen S, Evans DH. Typing and subtyping influenza virus using DNA microarrays and multiplex reverse transcriptase PCR. J Clin Microbiol 2001;39: 696-704.

14 Echevarria JE, Erdman DD, Swierkosz EM, et al. Simultaneous detection and identification of human parainfluenza viruses 1, 2, and 3 from clinical samples by multiplex PCR. J Clin Microbiol 1998;36: 1388-1391.

15 Osiowy C. Direct detection of respiratory syncytial virus, parainfluenza virus, and adenovirus in clinical respiratory specimens by a multiplex reverse transcription-PCR assay. J Clin Microbiol 1998;36: 3149-3154.

16 Vernet G. DNA-chip technology and infectious diseases. Virus Res 2002;82:65-71.

17 Jiang SS, Chen TC, Yang JY, et al. Sensitive and quantitative detection of severe acute respiratory syndrome coronavirus infection by real-time nested polymerase chain reaction. Clin Infect Dis 2004; 38:293-296. 